\title{
Suppression of metallothionein 3 gene expression by androgen in LNCaP prostate cancer cells
}

\author{
TAKASHI OTSUKA, AKI HAMADA, KAZUHIRO IGUCHI, SHIGEYUKI USUI and KAZUYUKI HIRANO \\ Laboratory of Pharmaceutics, Gifu Pharmaceutical University, Gifu, Gifu 501-1196, Japan
}

Received January 21, 2013; Accepted April 17, 2013

DOI: $10.3892 /$ br.2013.107

\begin{abstract}
Androgen deprivation therapy is the standard treatment for prostate cancer. However, tumors often progress towards a more aggressive phenotype despite treatment. Prostate tissue has a high zinc concentration, which may correlate with prostate cancer progression. Therefore, we investigated the effect of dihydrotestosterone (DHT) on the gene expression of metallothioneins (MTs) and zinc transporters in prostate cancer with quantitative real-time polymerase chain reaction (PCR). The MT3 gene expression in $\mathrm{LNCaP}$ cells was suppressed by DHT in a dose-dependent manner. However, it increased in a culture medium containing androgen-deficient charcoal-stripped fetal bovine serum (FBS). Bicalutamide, an androgen receptor antagonist, increased the gene expression of MT3 and partially reversed the suppression of MT3 gene expression induced by DHT. In PC-3 cells lacking androgen receptors, DHT and bicalutamide exerted no effect on MT3 gene expression. The reporter gene assay with a luciferase reporter plasmid containing the 5'-flanking region of MT3 demonstrated a decrease in luciferase activity caused by DHT that was reversed by bicalutamide. These results suggest that MT3 gene expression is downregulated by androgen.
\end{abstract}

\section{Introduction}

Androgen deprivation therapy is one of the standard treatments for prostate cancer, since the growth and progression of prostate cancer are primarily androgen-dependent (1). However, the progression of an androgen-dependent prostate cancer to an androgen-independent state is a well-established phenomenon (2). Zinc content, which is known to be higher in the prostate compared to any other tissue, has been found to be significantly lower in androgen-independent prostate cancers compared to androgen-dependent ones $(3,4)$. We previously reported that androgen-insensitive AIDL cells, which

Correspondence to: Dr Shigeyuki Usui, Laboratory of Pharmaceutics, Gifu Pharmaceutical University, 1-25-4 Daigaku-nishi, Gifu, Gifu 501-1196, Japan

E-mail: usui@gifu-pu.ac.jp

Key words: metallothionein 3, androgen, LNCaP, prostate were established by long-term culture of androgen-sensitive LNCaP cells in a hormone-deprived medium, exhibited a significantly lower zinc content compared to LNCaP cells (5).

Metallothioneins (MTs) and zinc transporters function to maintain cellular zinc homeostasis. MTs are small metal-binding proteins that exist as four isoforms in mammals. Metallothionein (MT)1 and MT2 are major isoforms expressed in the majority of tissues, whereas MT3 and MT4 are minor isoforms normally found in a limited number of tissues (6). The MT3 protein was first isolated as a growth-inhibiting factor from brain neurons and was found to be expressed at high levels in prostate cancer tissues (7). Zinc transporters are classified as the ZnT and ZIP families, belonging to the solute-linked carrier (SLC) gene families SLC30 and SLC39, respectively. SLC30A1 and SLC30A4 expression was reported to be decreased in patients with prostate cancer compared to those with benign prostatic hyperplasia $(8,9)$. SLC39A1 and SLC39A2 expression in prostate tumor tissues obtained from African-American patients was lower compared to that in Caucasian patients (10).

Since zinc levels in the prostate are known to decrease with the progression of prostate cancer during androgen deprivation therapy, we hypothesized that zinc exerts a preventative effect on cancer progression. We previously reported that zinc suppressed the invasiveness of prostate cancer cells and increased the sensitivity of cells to cytotoxic agents (11-13). Therefore, we investigated the effect of androgen on the gene expression of MTs and zinc transporters to elucidate the regulation of zinc levels by androgen in LNCaP cells and demonstrated that MT3 expression is downregulated by androgen.

\section{Materials and methods}

Materials. Dihydrotestosterone (DHT) was purchased from Wako Pure Chemical Industries, Ltd. (Osaka, Japan). Bicalutamide was obtained from Santa Cruz Biotechnology, Inc. (Santa Cruz, CA, USA). Charcoal-stripped fetal bovine serum (CS-FBS) was obtained from Invitrogen (Carlsbad, CA, USA). Phenol red-free RPMI-1640 medium was purchased from Sigma-Aldrich (St. Louis, MO, USA). All other chemicals were of analytical grade.

Cell culture. LNCaP human prostatic carcinoma cells and PC-3 cells were obtained from American Type Culture Collection (Rockville, MD, USA). Androgen-low-sensitive 
LNCaP-E9 cells have been previously described (14). Cells were cultured in RPMI-1640 medium containing 10\% fetal bovine serum (FBS) in a humidified atmosphere with $5 \% \mathrm{CO}_{2}$ at $37^{\circ} \mathrm{C}$.

Quantitative real-time reverse transcription-polymerase chain reaction ( $R T-P C R)$. Total RNA was extracted using TRIzol reagent (Invitrogen) and first-strand complementary DNA was synthesized from $5 \mu \mathrm{g}$ of total RNA using SuperScript III (Invitrogen) as previously described (14). Real-time monitoring of PCR reactions was performed using the Thermal Cycler Dice Real-Time system (Takara, Otsu, Japan) with the SYBR Premix Ex Taq (Takara). At the end of the reaction, a dissociation curve analysis was performed to assess the specificity of the product. PCR was performed under the following conditions: 35 cycles of $30 \mathrm{sec}$ at $95^{\circ} \mathrm{C}, 30 \mathrm{sec}$ at $58^{\circ} \mathrm{C}$ and $30 \mathrm{sec}$ at $72^{\circ} \mathrm{C}$ for $M T 1 \mathrm{~A}$, $M T 2 A$ and $M T 3 ; 35$ cycles of $30 \mathrm{sec}$ at $95^{\circ} \mathrm{C}, 20 \mathrm{sec}$ at $58^{\circ} \mathrm{C}$ and $30 \mathrm{sec}$ at $72^{\circ} \mathrm{C}$ for $M T 1 G$ and $M T 1 X ; 35$ cycles of $60 \mathrm{sec}$ at $94^{\circ} \mathrm{C}$, $60 \mathrm{sec}$ at $55^{\circ} \mathrm{C}$ and $60 \mathrm{sec}$ at $72^{\circ} \mathrm{C}$ for SLC3OAl and SLC39A1; 35 cycles of $30 \mathrm{sec}$ at $95^{\circ} \mathrm{C}, 30 \mathrm{sec}$ at $61^{\circ} \mathrm{C}$ and $30 \mathrm{sec}$ at $72^{\circ} \mathrm{C}$ for SLC30A2; and 35 cycles of $10 \mathrm{sec}$ at $95^{\circ} \mathrm{C}$ and $20 \mathrm{sec}$ at $60^{\circ} \mathrm{C}$ for glyceraldehyde 3-phosphate dehydrogenase (GAPDH). $G A P D H$, a housekeeping gene, was used for normalization of target mRNA expression. The primers used in this study are listed in Table I.

Plasmid construction. Genomic DNA from LNCaP cells was extracted using TRIzol reagent (Invitrogen) according to the manufacturer's instructions. The 5'-flanking region of the human MT3 gene between -905 and +285 bp was amplified by PCR from genomic DNA using primers containing restriction sites for KpnI and NheI, respectively. The sequences of the primers were as follows: sense, 5'-ACGGTACCTACTGCAGCCTCCTCAACCT-3'; antisense, 5'-ACGCTAGCGCTTCTCCAAGCAACTGGAC-3'. The fragment was ligated to a pGL3-basic firefly luciferase reporter vector (Promega, Madison, WI, USA).

Luciferase assay. LNCaP cells were seeded at a density of $2 \times 10^{5}$ cells/well into a 24 -well culture plate (Nalge Nunc International, Rochester, NY, USA). After $24 \mathrm{~h}$, the medium was changed to phenol red-free RPMI-1640 supplemented with DHT and/or bicalutamide. Cells were then cotransfected with $0.7 \mu \mathrm{g}$ of pGL3-MT3 (-905 to +285) firefly luciferase reporter plasmid and $0.1 \mu \mathrm{g}$ of Renilla luciferase plasmid pRL-CMV using Lipofectamine ${ }^{\circledR} 2000$ (Invitrogen), according to the manufacturer's instructions. Forty-eight hours after transfection, cell lysates were prepared and luciferase activities were measured using the Dual-Luciferase Reporter Assay system (Promega). Firefly luciferase activity was normalized to Renilla luciferase activity.

Statistical analysis. Significance was assessed by a one-way ANOVA followed by Dunnett's test using Prism4 software (GraphPad Software, San Diego, CA, USA). P $<0.05$ was considered to indicate a statistically significant difference.

\section{Results}

Effect of androgen on zinc transporter and metallothionein expression in prostate cancer cells. The effect of DHT on the
Table I. Primer sequences designed for real-time reverse transcription-polymerase chain reaction.

\begin{tabular}{|c|c|}
\hline Gene name & Sequence \\
\hline \multicolumn{2}{|l|}{ GAPDH } \\
\hline Sense & 5'-CCAGCAAGAGCACAAGAGGA-3' \\
\hline Antisense & 5'-GCAACTGTGAGGAGGGGAGA-3' \\
\hline \multicolumn{2}{|l|}{ SLC $30 A 1$} \\
\hline Sense & 5'-TGTGAACTTGCCTGCAGAAC-3' \\
\hline Antisense & 5'-GCTTTAGTCCTCCTGGGCTT-3' \\
\hline \multicolumn{2}{|l|}{ SLC $30 A 2$} \\
\hline Sense & 5'-AGATGCAAGAGGGGAAACCT-3' \\
\hline Antisense & 5'-TGGCAGAGACAGACCTTGTG-3' \\
\hline \multicolumn{2}{|l|}{ SLC39A1 } \\
\hline Sense & 5'-GTCCTGGTGATGGAGCAGAT-3' \\
\hline Antisense & 5'-CCGATGCCTAGAGGTGTCAT-3' \\
\hline \multicolumn{2}{|l|}{ MT1A } \\
\hline Sense & 5'-CTCGAAATGGACCCCAACT-3' \\
\hline Antisense & 5'-ATATCTTCGAGCAGGGCTGTC-3' \\
\hline \multicolumn{2}{|l|}{$M T 1 G$} \\
\hline Sense & 5'-GCCAGCTCCTGCAAGTGCAA-3' \\
\hline Antisense & 5'-TCTCCGATGCCCCTTTGCAG-3' \\
\hline \multicolumn{2}{|l|}{ MT1X } \\
\hline Sense & 5'-TCTCCTTGCCTCGAAATGGAC-3' \\
\hline Antisense & 5'-GGGGCACACTTGGCACAGC-3' \\
\hline \multicolumn{2}{|l|}{$M T 2 A$} \\
\hline Sense & 5'-CCGACTCTAGCCGCCTCTT-3' \\
\hline Antisense & 5'-GTGGAAGTCGCGTTCTTTACA-3' \\
\hline \multicolumn{2}{|l|}{ MT3 } \\
\hline Sense & 5'-GCTGAGGCAGAAGCAGAGAAG-3' \\
\hline Antisense & 5'-TCATTCCTCCAAGGTCAGCA-3' \\
\hline
\end{tabular}

mRNA expression of zinc transporters and MTs in prostate cancer cells was first assessed by real-time RT-PCR analysis. As shown in Fig. 1, DHT decreased the expression of MT3 in androgen-sensitive LNCaP cells in a dose-dependent manner, but did not affect SLC30A1, SLC30A2, SLC39A1, MT1A, $M T 1 G, M T 1 X$ or $M T 2 A$ expression. In PC-3 cells lacking androgen receptors, DHT exerted no effect on the expression of MT3 (Fig. 2B). In addition, MT3 expression in LNCaP cells was markedly higher with the medium containing androgen-deficient CS-FBS compared to the normal FBS (Fig. 2A). The MT3 expression in androgen-low-sensitive LNCaP-E9 cells was significantly higher in the medium containing CS-FBS compared to the normal FBS; however, the expression was less pronounced compared to that in LNCaP cells. There were no differences in MT3 expression between PC-3 cells in the medium containing FBS and those in CS-FBS. The effect of bicalutamide, an androgen receptor antagonist, on MT3 expression was then examined. Bicalutamide increased the mRNA expression in LNCaP cells, whereas it exerted no effect on PC-3 cells (Fig. 2C). Moreover, the suppression of MT3 expression triggered by DHT was inhibited in the 

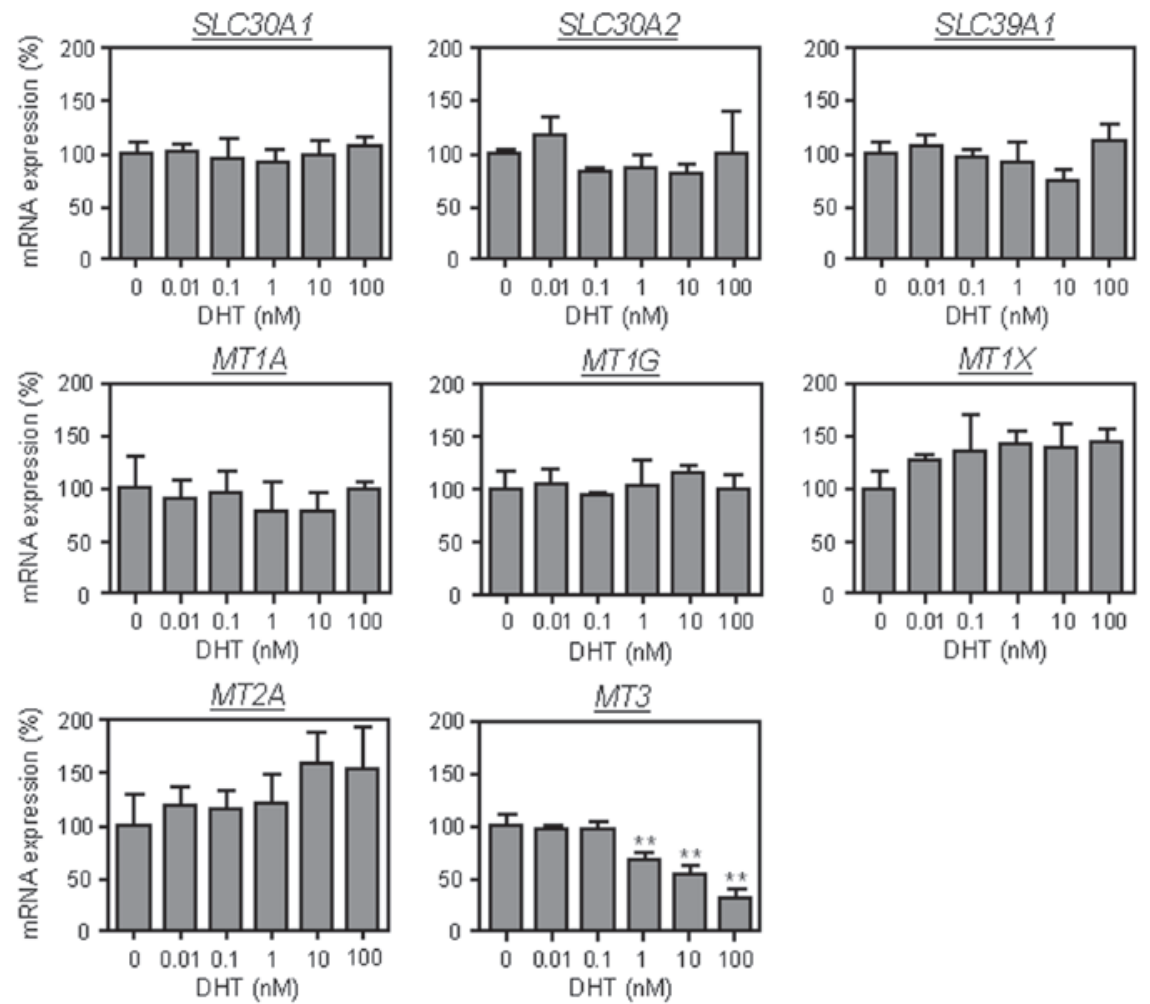

Figure 1. Effect of dihydrotestosterone (DHT) on zinc transporter and metallothionein mRNA expression. LNCaP cells were cultured in phenol red-free RPMI-1640 medium supplemented with $2 \%$ charcoal-stripped fetal bovine serum for 1 day and then treated with the indicated concentrations of DHT for $48 \mathrm{~h}$. Total RNA was isolated from cells and subjected to real-time reverse transcription-polymerase chain reaction analysis. ${ }^{* *} \mathrm{P}<0.01 \mathrm{vs}$. untreated LNCaP cells.

A
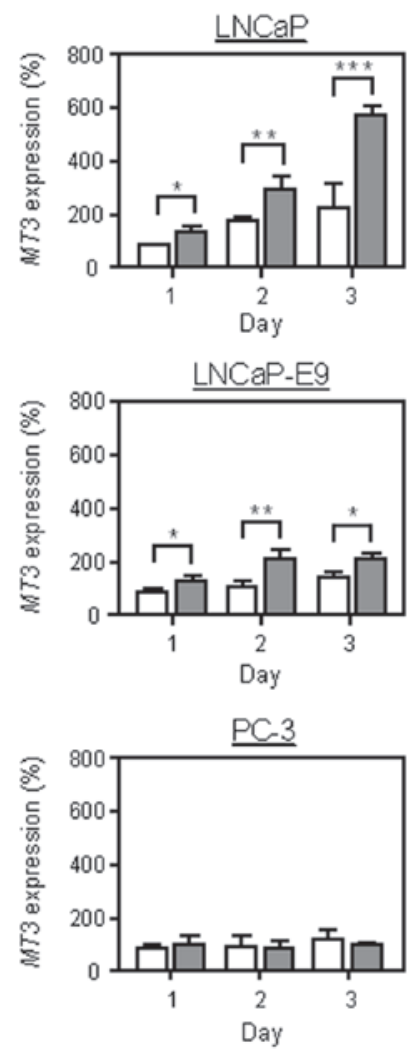

B

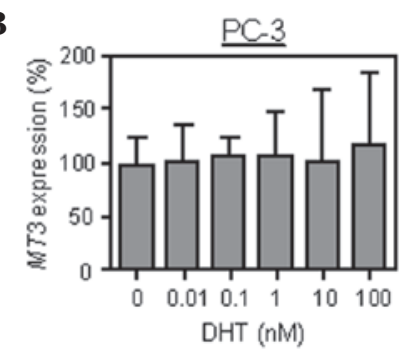

C

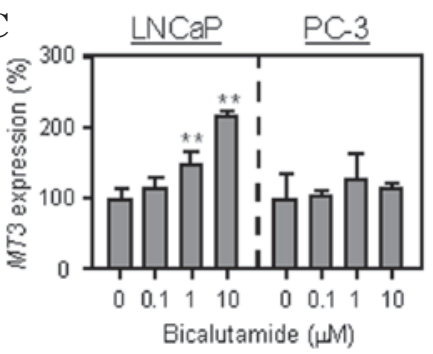

D

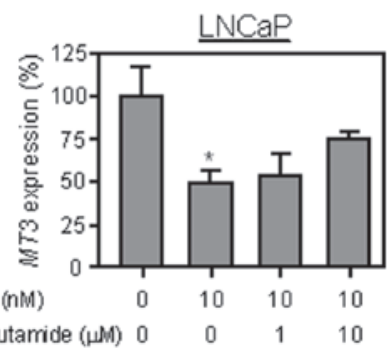

Figure 2. Androgen regulates MT3 mRNA expression in LNCaP cells. (A) Cells were cultured in RPMI-1640 medium supplemented with 5\% fetal bovine serum (white bars) or phenol red-free RPMI-1640 medium supplemented with 5\% charcoal-stripped fetal bovine serum (CS-FBS) (black bars) for 1,2 and 3 days. (B) PC-3 cells were cultured in phenol red-free RPMI-1640 medium supplemented with $2 \%$ CS-FBS for 1 day and then treated with the indicated concentrations of dihydrotestosterone (DHT) for $48 \mathrm{~h}$. (C) Cells were treated with the indicated concentrations of bicalutamide for 48 h. (D) LNCaP cells were treated with $10 \mathrm{nM}$ DHT and the indicated concentrations of bicalutamide for $48 \mathrm{~h}$. After incubation, total RNA was isolated from cells and subjected to real-time reverse transcription-polymerase chain reaction analysis. ${ }^{*} \mathrm{P}<0.05,{ }^{* *} \mathrm{P}<0.01,{ }^{* * *} \mathrm{P}<0.001$ vs. control. 

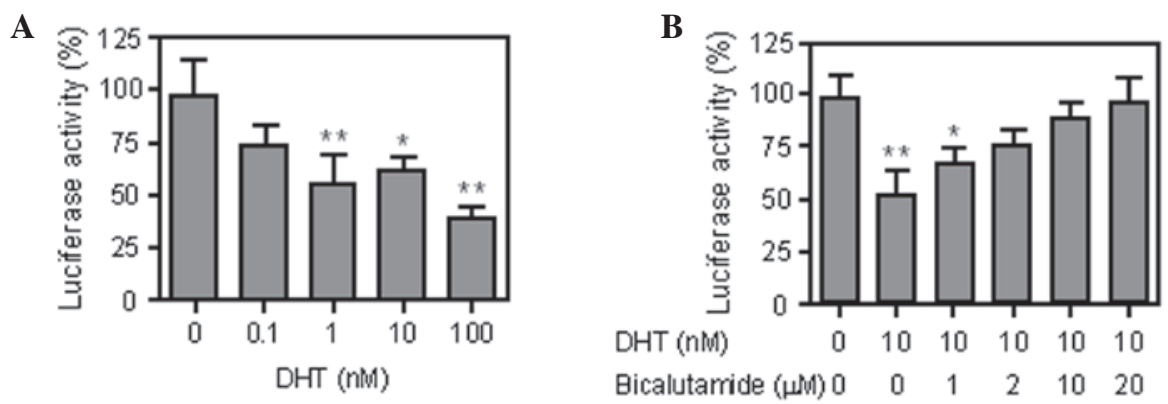

Figure 3. Androgen regulates MT3 transcriptional activity in LNCaP cells. LNCaP cells were transfected with pGL3-basic vector containing the $M T 3$ upstream region (-905 to +285) and phRL-CMV. Cells were then treated with the indicated concentration of (A) dihydrotestosterone (DHT) or (B) DHT plus bicalutamide. After $48 \mathrm{~h}$, cell lysates were prepared. Firefly luciferase activity was measured using the Dual-Luciferase Reporter Assay system and normalized with Renilla luciferase activity. ${ }^{*} \mathrm{P}<0.05,{ }^{* *} \mathrm{P}<0.01$ vs. untreated LNCaP cells

presence of bicalutamide (Fig. 2D). These results suggest that MT3 expression is downregulated by androgen.

Androgen regulates $M T 3$ transcriptional activity in LNCaP cells. The luciferase reporter assay was then performed using MT3 reporter constructs, to determine whether the downregulation of MT3 expression by androgen is due to transcriptional regulation. As shown in Fig. 3, DHT decreased luciferase activity in LNCaP cells and this decrease was reversed by bicalutamide. Taken together, these results suggest that MT3 expression may be regulated by androgen transcriptional control in LNCaP cells.

\section{Discussion}

In this study, we demonstrated that MT3 expression was regulated by androgen in prostate cancer cells. Although DHT decreased MT3 expression in androgen-sensitive LNCaP cells, bicalutamide exerted the opposite effect. The induction of MT3 expression by androgen withdrawal was lower in androgen-low-sensitive LNCaP-E9 cells compared to that in LNCaP cells. In addition, no change was observed in MT3 expression following androgen withdrawal or treatment with DHT or bicalutamide in PC-3 cells lacking androgen receptors. These results suggest that the expression of MT3 in LNCaP cells is downregulated by androgen. The androgen receptor binds to specific DNA motifs known as androgen-response elements (AREs) in the regulatory regions of target genes. AREs comprise two 6-bp elements separated by a 3-bp spacer, 5'-AGAACAnnnTGTTCT-3' (15). The sequence (5'-TCTTGTnnnACAGGC-3'), which is similar to the reverse sequence of ARE, is found upstream in the MT3 gene at the position -871 to -857 .

Previous studies suggested that the regulation of MT3 expression appears to be complicated due to cell-type specificity and differences between species (7,16-18). Specifically, MT3 expression was observed to be upregulated by androgen in rodent tissues $(17,19)$. In a previous study, we reported that MT3 expression in the lateral lobe of the rat prostate was decreased following castration (20), a finding inconsistent with our present results, according to which MT3 mRNA expression in LNCaP cells is downregulated by androgen. Therefore, the 5'-flanking region of the MT3 gene was compared between rats and humans to investigate the opposite regulation of MT3 expression in these species. ARE and the reverse sequence of ARE were not found within $3 \mathrm{~kb}$ of the 5'-upstream region of the MT3 gene in rats, although the sequence exists in this $3-\mathrm{kb}$ region in humans. The existence of ARE and the reverse sequence of ARE may be responsible for the differences in androgen-regulated MT3 expression between the two species.

The mechanisms underlying the transition to the aggressive phenotype following androgen deprivation therapy have yet to be elucidated. However, one of the reasons considered is the altered gene expression associated with alterations in the tumor malignant potential triggered by androgen withdrawal. In this study, we demonstrated that MT3 expression was downregulated by androgen in LNCaP cells. MT3 has been shown to be involved in growth inhibition, prevention of hypoxic damage and chemotherapy resistance (21-23). These results suggest that the androgenic regulation of MT3 expression may be the mechanism underlying the progression of prostate cancer.

\section{References}

1. Huggins C and Hodges CV: Studies on prostatic cancer. I. The effect of castration, of estrogen and of androgen injection on serum phosphatases in metastatic carcinoma of the prostate. Cancer Res 1: 293-297, 1941.

2. Emmett JL, Green LF and Papantoniou A: Endocrine therapy in carcinoma of the prostate gland: 10-year survival studies. J Urol 83: 471-484, 1960.

3. Shiina $H$, Igawa $M$ and Ishibe $T$ : Estramustine-binding protein to dihydrotestosterone ratio in human prostatic carcinoma: a new marker for predicting disease progression. Br J Urol 77: 96-101, 1996.

4. Shiina $\mathrm{H}$, Igawa $\mathrm{M}$ and Ishibe $\mathrm{T}$ : Clinical study on estramustine binding protein (EMBP) in human prostate. Prostate 29: 169-176, 1996.

5. Iguchi K, Otsuka T, Usui S, Ishii K, Onishi T, Sugimura Y and Hirano K: Zinc and metallothionein levels and expression of zinc transporters in androgen-independent subline of LNCaP cells. J Androl 25: 154-161, 2004.

6. Hidalgo J, Chung R, Penkowa M and Vašák M: Structure and function of vertebrate metallothioneins. In: Metallothioneins and Related Chelators. Sigel A, Sigel H and Sigel RKO (eds.) The Royal Society of Chemistry, Cambridge, pp279-317, 2009.

7. Garrett SH, Sens MA, Shukla D, Nestor S, Somji S, Todd JH and Sens DA: Metallothionein isoform 3 expression in the human prostate and cancer-derived cell lines. Prostate 41: 196-202, 1999.

8. Hasumi M, Suzuki K, Matsui H, Koike H, Ito K and Yamanaka H: Regulation of metallothionein and zinc transporter expression in human prostate cancer cells and tissues. Cancer Lett 200: 187-195, 2003. 
9. Henshall SM, Afar DE, Rasiah KK, Horvath LG, Gish K, Caras I, Ramakrishnan V, Wong M, Jeffry U, Kench JG, Quinn DI, Turner JJ, Delprado W, Lee CS, Golovsky D, Brenner PC, O'Neill GF, Kooner R, Stricker PD, Grygiel JJ, Mack DH and Sutherland RL: Expression of the zinc transporter ZnT4 is decreased in the progression from early prostate disease to invasive prostate cancer. Oncogene 22: 6005-6012, 2003.

10. Rishi I, Baidouri H, Abbasi JA, Bullard-Dillard R Kajdacsy-Balla A, Pestaner JP, Skacel M, Tubbs R and Bagasra O: Prostate cancer in African American men is associated with downregulation of zinc transporters. Appl Immunohistochem Mol Morphol 11: 253-260, 2003.

11. Iguchi K, Hamatake M, Ishida R, Usami Y, Adachi T, Yamamoto H, Koshida K, Uchibayashi T and Hirano K: Induction of necrosis by zinc in prostate carcinoma cells and identification of proteins increased in association with this induction. Eur J Biochem 253: 766-770, 1998.

12. Ishii K, Usui S, Sugimura Y, Yoshida S, Hioki T, Tatematsu M, Yamamoto $\mathrm{H}$ and Hirano $\mathrm{K}$ : Aminopeptidase $\mathrm{N}$ regulated by zinc in human prostate participates in tumor cell invasion. Int J Cancer 92: 49-54, 2001

13. Ishii K, Otsuka T, Iguchi K, Usui S, Yamamoto H, Sugimura $Y$, Yoshikawa K, Hayward SW and Hirano K: Evidence that the prostate-specific antigen (PSA)/ $\mathrm{Zn}^{2+}$ axis may play a role in human prostate cancer cell invasion. Cancer Lett 207: 79-87, 2004.

14. Iguchi K, Ishii K, Nakano T, Otsuka T, Usui S, Sugimura Y and Hirano K: Isolation and characterization of LNCaP sublines differing in hormone sensitivity. J Androl 28: 670-678, 2007.

15. Verrijdt G, Haelens A and Claessens F: Selective DNA recognition by the androgen receptor as a mechanism for hormone-specific regulation of gene expression. Mol Genet Metab 78: 175-185, 2003.
16. Belloso E, Hernandez J, Giralt M, Kille P and Hidalgo J: Effect of stress on mouse and rat brain metallothionein I and III mRNA levels. Neuroendocrinology 64: 430-439, 1996.

17. Moffatt $P$ and Séguin C: Expression of the gene encoding metallothionein-3 in organs of the reproductive system. DNA Cell Biol 17: 501-510, 1998

18. Wei H, Desouki MM, Lin S, Xiao D, Franklin RB and Feng P: Differential expression of metallothioneins (MTs) 1, 2, and 3 in response to zinc treatment in human prostate normal and malignant cells and tissues. Mol Cancer 7: 7, 2008

19. Cyr DG, Dufresne J, Pillet S, Alfieri TJ and Hermo L: Expression and regulation of metallothioneins in the rat epididymis. J Androl 22: 124-135, 2001.

20. Iguchi K, Morihara N, Usui S, Hayama M, Sugimura Y and Hirano K: Castration- and aging-induced changes in the expression of zinc transporter and metallothionein in rat prostate. J Androl 32: 144-150, 2011.

21. Dutta R, Sens DA, Somji S, Sens MA and Garrett SH: Metallothionein isoform 3 expression inhibits cell growth and increases drug resistance of PC-3 prostate cancer cells. Prostate 52: 89-97, 2002.

22. Gurel V, Sens DA, Somji S, Garrett SH, Nath J and Sens MA: Stable transfection and overexpression of metallothionein isoform 3 inhibits the growth of MCF-7 and Hs578T cells but not that of T-47D or MDA-MB-231 cells. Breast Cancer Res Treat 80: 181-191, 2003.

23. Wang B, Wood IS and Trayhurn P: PCR arrays identify metallothionein-3 as a highly hypoxia-inducible gene in human adipocytes. Biochem Biophys Res Commun 368: 88-93, 2008. 